\title{
Transformations of Global Cooperation Processes as a Strategy of Sustainable Social Development in the Context of Research and Education
}

\author{
Viktor Viktorovich Zinchenko ${ }^{{ }^{*}}$, Mykhailo Ivanovych Boichenko ${ }^{2}$, and Oleksandr \\ Serhiyovych Polishchuk ${ }^{3}$ and Iryna Ivanivna Drach ${ }^{4}$ \\ 1 Doctor of Sciences (Philosophical), Principal researcher in Department of University Research Activities of the Institute of Higher Education of the \\ National Academy of Educational Sciences of Ukraine, Kyiv, Ukraine \\ 2 Doctor of Sciences (Philosophical), Professor of Department of Theoretical and Practical Philosophy, Taras Shevchenko National University of Kyiv, \\ Kyiv, Ukraine \\ 3 Doctor of Sciences (Philosophical), vice-rector of Khmelnytskyi Humanitarian-Pedagogical Academy, Khmelnytskyi, Ukraine \\ 4 Doctor Habilitated of Education Sciences, First Deputy Director of the Institute of Higher Education of the National Academy of Educational Sciences \\ of Ukraine, Ukraine
}

\begin{abstract}
Globalization involves the merging of societies and economies (and all their institutions - including educational and scientific) of all countries into a single socio-economic system with the prospect of more effective political coordination among them. There is a need for a new type of social contract between society and citizens, which must necessarily be included in modern institutional systems. This contract manifests itself differently on the basis of different national cultures, so the socio-economic development should be based on intercultural dialogue between different countries, social systems and civic institutions. The internationalization and integration of higher education in the global and international aspect raises many new questions for theory and practice: what patterns, forms, methods of management are universal, and which of them are specific. It is assumed that it is necessary to identify and conceptualize the essential interdependence of systemic and functional characteristics of the institutional dimension of global transformations of world development.
\end{abstract}

\section{Introduction}

In modern world there has been a diversification of different higher education models. At the same time, the multivariate and diversity of higher education models do not exclude their uniqueness and their common problems.

The diversity of higher education models does not exclude their common problems related to:

- the need in permanent adaptation of educational programs to modern needs of society;

- the increase of requirements to the level and quality of education.

The internationalization and integration of higher education in the global and international aspect raises many new questions to theory and practice.

\footnotetext{
Corresponding author:zinchenko.72@gmail.com
} 
The most important of them are the following: what is common and specific in education and science, what patterns, forms, methods of management are universal, and which operate in the range of specific conditions in different countries, what is the best way to perform the functions of education and science in international activities, what are the characteristics of national style in education and development of the university as an institution for education, in organizational behavior, management systems, how important these characteristics are for achieving the desired results.

Currently the word "globalization" is being increasingly used to describe the processes going on in the world. The change of terms hides significant changes in the processes occurring on a global scale.

Globalization involves the merging of societies and economies (and all their institutions including educational and scientific) of all countries into a single socio-economic system with the prospect of similar political and ideological unification and possible (though not always desirable) cultural and spiritual standardization within the world social system.

As a result, there is a need for integrative conceptualization and scientific synthesis of existing concepts and theories in this direction. It seems to us that a new type of social contract between society and citizens has to be formed, which must be necessarily included in modern institutional systems.

At the same time, it manifests itself differently on the basis of different national cultures, and therefore, the specifics of socio-economic development in today's globalized world should be based on intercultural dialogue among different countries, social systems and civic institutions. Finally, such system of institutionalization must include ideas for security of society and culture from the destructive influence of anti-culture and anti-values.

\section{Research methodology}

The development of theory, analysis and consideration of positions and concepts should be based on the comparative analysis method, and the grounds for such analysis are specified for each case - a certain comparison of authors' studies and ideas not belonging to one direction of ideological school. They are considered as methodological and theoretical prerequisites for a diverse, objectively determined process for understanding the transformations of socio-economic structures and the institutionalization of civil society in the context of globalization as a holistic, interconnected phenomenon.

On this basis, the possibility for authentic conceptual understanding of the originality of ideas, their role in global socio-economic processes and human life is being identified and realized.

Due to such approach, the study focuses on moments that do not always appear to a thinker as defining or cornerstone, while other provisions are involved only to the extent they affect the problems of general and special globalism.

We regard a promising "model" of research to be the one that isolates and integrates the transformational and structural aspects of the knowledge fields on the trends of institutionalization in the context of globalization processes. These ideas are used as methodological bases for defining the principles, attitudes of socio-economic activity in the context of global development and transformation processes $[1,2]$.

In modern globalism, an imitative homeostatic avalanche-like model of crisis degradation of a society, living in line with the principles of consumption, has been formed, threatening by falling intelligence development below the critical mark and consequently by cessation of technological progress and sharp increase of mortality compared to births $[3,4]$. This presupposes an urgent need to develop an institutional approach in social cognition and social philosophy.

At the same time, civil and institutional practice in the context of globalization requires a qualitative methodological background. It is the socio-philosophical system of integrative 
global paradigm of civil institutionalization that should become this background based on generalization of achievements, in particular, world-system analysis, macrosocial approach, concept of dependence (dependent development) and post-imperialism, theories of subsidiarity, communitarianism, concepts of social deliberativeness and libertarianism in the context of the formation of a global-stage understanding of social development.

It is assumed that it is necessary to identify and conceptualize the essential interdependence and interonditionality of systemic and functional characteristics of the institutional dimension for global transformations of world development, its systemic connections in global reality on the basis of the author's world-system global-stage concept as an institutionalized process for functioning of deliberative social economic development in the institutional model of globalization.

The research hypothesis also assumes that the process for democratization of institutions of society, education and science can be effectively investigated on the basis of analysis of the decision-making process in the field of socio-economic activities, consisting of two relatively independent factors: a community, as a group, having the ability to selforganization and self-government, on the one hand, and the structures and bodies of social and administrative management, which carries out the will of the state and society, but capable of transferring some power in self-government, on the other hand.

In this regard, it is necessary to form a global-stage understanding for world global development and its transformations as a process of reproducing the internal necessity for development not of each socio-economic socio-historical formation, taken separately, but only as a collection of all those that existed in the past and exist now socio-economic historical systems combined, i.e human society as a whole, which necessarily involves the study of the interaction between individual specific societies as socio-economic historical entities and their various systems and institutions. Socio-historical systems always influence each other in one way or another, and often the action of one socio-economic historical system on another has led to significant changes in the structure of the latter's institutions (including in the fields of education and science). The term "social induction" is being introduced and used in relation to the above-mentioned institutional type of influence; one of the results of this is that under the influence of socio-historical systems of higher type and their institutions - socio-historical systems of lower, less developed type, are transformed into systems of the same type as those that affect them, i.e pulled up to their level. All existing socio-economic historical systems form a certain institutionalized integrity and unity - the world's socio-economic historical space.

\section{Results of the research}

The country's place in the modern world today is more determined by the quality of human capital, the state of education and the degree science and technology are being used in production.

Wealth, in the volume of labor and raw materials, can be less and less regarded as a competitive advantage - in accordance with how the share of these factors in creating the value of all products is being lowered.

As a result of such irreversible development, it is becoming increasingly likely that developing countries can succeed solely on the basis of their minerals and, consequently, cheaper labor force. However, this process is still far from identical to the real universalization of the global community.

In other words, in addition to certain realities of globalization, institutional transformations for sustainable development of society in the context of internationalization of higher education and science, in the world there also coexists no less real trends of regionalization, dissociation and even antisocialization. 
Strategies of higher education in the light of generational change, as a condition for sustainable development of society, are important in the dimension of internationalization. Those who teach are the representatives of the middle and older generations, while those who learn are mostly the younger generation - the next step should be the sociological and historical definition of these generations and the specification of their characteristics as stable social groups in society.

The younger generation is incomparably more mobile, and therefore more open to the internationalization of education in the literal sense of the word - thanks to studying abroad: there is a complete immersion in international experience. However, the middle and older generations may also be involved in internationalization, although this already requires special government programs and special personal efforts, starting with in-depth study of a foreign language (especially English), mastering foreign teaching methods, and foreign study material. Internships or teaching abroad for these generations are also available, but more limited than for young $[5,6]$.

The internationalization of education is ambivalent to overcome the crisis in Ukraine: Ukrainian education can lose in global competition (and with a high degree of probability), and can adopt the world's best examples of educational practices and even propose something new and impressively useful for the world education system. To achieve some positive and competitive educational result is a task for specific educational communities:

"Overcoming the current crisis in the education system of Ukraine is possible through a clear definition of the goals and basic values of education for specific participants in the educational process - only in this case, systemic goals and values become the values and goals for individual educational communities. Teachers, professors and other subjects in delivering education appear then to be specific pedagogical teams, united by explicit educational values and goals, which are clearly correlated, on the one hand, with the objectives of the national education system, and, on the other hand, with the motivation of educational activities of teachers themselves" [5].

Such a correlation, unfortunately, is still not clear and stable - both due to too rapid and insufficiently consistent changes in the national education system, and due to the weak providing of the value-motivational base of teachers (both material and ideological).

But the main factor of motivation in the field of education, both for teachers and students, should be fair competition, and competition focused primarily on spiritual goals.

"The inevitable competition in education, which is particularly dramatic in overcoming its systemic crisis, has positive consequences if it is carried out as a competition for the best embodiment of virtues, for excellence in teahing and learning" [5]. One of the main tasks of Ukrainian education is to overcome the remnants of colonial culture, which is being manifested in the imitation of Russian models in pedagogy.

The task of higher education is to achieve self-sufficiency of the methodological system, to complete the development of professional terminology, to improve national systems of teacher training both as to be global and as self-sufficient staff. All this requires a reorientation in the implementation of personnel policy in the education system to a new generation of pedagogy.

In studying the future of society and institutional transformations for sustainable development of society in the context of internationalization of higher education and science, emphasis should be placed evenly on the analysis of values and analysis of social institutions, which will help to realize the real mechanisms for practical construction of a new society taking into account globalization processes.

Referring to the immanent content of institutional problems of institutional transformations for sustainable development of society in the context of internationalization of higher education and science, it should be noted that scientific reflection has always been definitely present in the depths of globalist knowledge, as revealing of its content was 
associated with revealing of comprehension in the unity of being natural and soial, and inside the latter - in the educational, scientific, political, economic, etc being. Such unity realizes the target function and provides a governing influence in relation to society in the form of practical and transformational activities or social, economic and political power over space [7].

In modern conditions, the "contradictions of globalism and imperialism" cannot be subsumed under general formulas, such as the "universal contradictions between labor and capitalism" and even more, they cannot be resolved by them.

Modern models of institutionalization and self-organization of social systems should be built around the basic foundations: intellectual and moral education, civic institutionalization, socially significant models of social governance.

The study of general multicultural contexts of social development makes it obvious that the development of a new type of social development should become a priority area of social institutionalization.

Institutionalized civil society is a socio-cultural factor that includes a person's attitude to the means not only of material production, but also of their self-production as a social, cultural being.

The idea of civil society expresses the historical trend of transition to freedom from political and economic determinism, so that a person becomes a co-owner of the general conditions of his personal development, regardless of his socio-economic functions and roles.

For modern scientific thought, social science and socio-philosophical, economic and political and managerial theories, the integration of the developed societies in the modern "neo-capitalist" (or "neo-industrial", "post-industrial", "late capitalist" in other terminology) phase of their development is an objet for special studies on how modern developed countries manage to institutionalize and control socio-economic and political relations.

This is primarily an analysis of global institutional, ideological and social transformations, the functioning of ideology, education and media, methods of limiting social struggle within a formalized social system, and especially within the development of existing social institutions and, in particular, control over market.

Modern science states that in modern society there are social states and forces alien to man, which not only failed to weaken, but moreover - today man and humanity are in such severe dependencies and dangers that not only threaten to turn them into objects of insubordinate by them social relations, but also threaten on a global scale the very foundations of human life. These problems can only be solved on a global scale.

In the new economy, wealth is determined by the possession of humane capital knowledge has become not only an independent factor of production, but also the main one in the whole system of factors. The formation of a new economy is the result in the development of new knowledge. Estimates show that the doubling of knowledge occurs every decade. This is due to the fact that they, in the form of information as systematized data, are changing the appearance of the modern world at an increasing rate.

There is a need not only to improve the institutional level of global society, but also to radically restructure in thinking, develop and implement new approaches, organizational forms and methods for designing strategies for its development. The concept of globalization has become a point from which the processes of social transformation and institutionalization are considered, or more precisely, transformational institutionalization.

Globalization is a dual-transformational phenomenon, because from the very beginning it has been in a state of so-called dynamic equilibrium, i.e constantly accompanied by equal and equally important phenomena - evolution, progress and revolution (social, economic and industrial, political and legal, scientific and technical, state and ideological, etc.) on the 
one hand, and regress, devolution on the other hand. However, it is the revolution (worldclass revolutionary transformations) that is both a condition and a dialectical state of globalization. Therefore, this process (globalization) occurs simultaneously in the forms of integration, unification, internationalization, expansion, and in regionalization, deglobalization, alterglobalization and so on.

The current education system is still "teaching" society the tasks and goals for sustainable development on a small and insufficient scale [8].

However, the official program document (Resolution) of the UN General Assembly formulates an appropriate global strategy "Transforming our world: the 2030 Agenda for Sustainable Development". Sustainable Development Goals (SDGs) are the key areas for implementing this global comprehensive multi-level strategy for social, governmental and institutional sustainable development [9].

Education is one of the crucial prerequisites for the implementation of the UN global strategy "Agenda 2030". Therefore, education has a key role in the vision of a just, peaceful and sustainable society (global, continental, regional and national).

International and European comprehensive strategy for sustainable social development "Transforming our world: the 2030 Agenda for Sustainable Development" at the global level of education and science offers a mechanism for "ensuring inclusive and equitable quality education and promoting lifelong learning opportunities for all".

The strategy envisages providing and allowing everyone to complete free, fair and quality primary, secondary and higher education, which will lead to appropriate and effective results of sustainable social development of both individual states and the global system. It is also necessary to create preconditions for ensuring access for all, regardless of social, sexual, racial, ethnic origin to quality education at all levels, and to create appropriate conditions for this by 2030, which will allow them to successfully move to the next educational levels and carry out lifelong learning. .

To do this, all levels, models and systems of education (through the model of "education for sustainable development") must be transformed so that learners acquire the knowledge and skills needed for sustainable development including among others, through education for sustainable development and sustainable lifestyles, human rights, gender equality, promoting a culture of peace and non-violence, through global civic education and the recognition of cultural diversity and the contribution of culture to sustainable development. Thus, Agenda 2030 sets practical challenges for governments to ensure, through the transformation of the education system ("education for sustainable development"), the maximum conditions for all people to participate (through the acquisition of quality knowledge and skills through education) in social-state and economic and political development [10].

Almost every developed country has extensive experience in building a system of higher education. The results of the analysis of this experience can contribute to the development and enrichment of the domestic education system, avoid the recurrence of mistakes and the opportunity to discover new approaches to solving a number of problems in this area [3]. Therefore, based on this, we believe that it is impossible to claim a strategy for modernization of educational and scientific reforms that affect the problems of educational and scientific institute of society in the management of scientific and educational space and not analyze existing models, schools, directions, their classification in modern philosophy of education. This already applies to both the field of the social component of the philosophy of education and the field of education management.

Today's world is characterized by a significant degree of integration and internationalization. National economies, inter-social relations, and interstate relations are gradually becoming more integrated. There has been a kind of "compression" of the world space, which requires new forms of relationships and institutional transformations for the 
sustainable development of society in the context of the internationalization of higher education and science. It is worth to take into account that "the presence of an individual at the university contributes to the creation of collective action, which is formed around competencies that contribute to further development and subordination at the highest level of social development" [11].

The reality is that globalization is an objective and absolutely inevitable phenomenon of modernity, which can be slowed down by means of economic policy (which happens in some cases), but can not be stopped or "canceled" because it is an imperative demand of modern society and scientific and technical progress.

In recent decades, there has been an increase in integration processes in the world, the development of trends towards joint solution of their problems. Another difference is related to the scientific and technological revolution and the formation of the "information society".

The revolution in technological processes, in turn, is the cause of significant changes in the hierarchy of the nation, a prerequisite for which are the institutional transformations for sustainable development of society in the context of the internationalization of higher education and science.

Cooperation at all levels is crucial for sustainable development. Governments and civil society, private sector, education sector and individuals must work together to make progress in reshaping the world. The focus is on sustainable development, people need to focus more on its issues in the education and training system.

\section{Conclusions}

Education institutions and establishments should teach how to work together in partnership, develop skills for sustainable development, develop critical thinking, share responsibility between students and the teaching team. Education institutions can be examples of sustainable lifestyles.

The process for democratization of institutes of society, education and science can be effectively changed by decision-making in the field of socio-economic activities, education and science, consisting of two relatively independent factors: a community, as a group, having the ability to self-organization and self-government, on the one hand, and the structures and bodies of social and administrative management, which carries out the will of the state and society, but capable of transferring some power in self-government, on the other hand.

Specific directions for the key areas of the educational goal for global sustainable development (at all levels of education) to be included in the education and training system are the following:

- Education for sustainable development.

- Global civic education and global learning.

- Political education.

- Ethical and moral education.

- Environmental education.

- Gender education issues / Equality in all educational aspects.

- Intercultural learning.

- Education in the field of individual rights.

Continuity of education in the processes of internationalization, its intensity can be ensured only under two conditions of a fundamental nature.

First is the use of the latest, affordable and technically equipped high learning technologies, mastery of knowledge. 
Second is perfect mastery of methodology for independent research by a person. The created structure should provide equal conditions for equal choice of scientific and educational actions, excluding coercion and domination.

That is, sustainable development of society in the context of internationalization of higher education and science, global development and transformations in the process of institutionalization of the global system is a holistic and multilevel sphere of interaction of economies, societies, states, social institutions, cultures, peoples, nations, worldviews influencing both national models of education and science, and change of a global educational and scientific paradigm.

Interdisciplinary links are important for common thinking on the environmental, economic and social dimensions. In addition, education for sustainable development, global citizenship education, and other learning principles and educational approaches provide an educational framework for sustainability in all its dimensions. The learning process should develop knowledge, competences and abilities, values and attitudes so that young people can play an active role in solving local and global social, economic and environmental problems.

In this sense, education raises awareness of the complexity of global challenges and promotes critical reflection and systematic and future-oriented thinking and, ultimately, action.

\section{References}

1. V. V Zinchenko, Actual Probl. Econ. 134, 10 (2012)

2. P. Dutta, J. Contemp. Gov. Public Policy 1, 82 (2020)

3. O. F. Williams, Sustainable Development: The Un Millennium Development Goals, the Un Global Compact, and the Common Good (University of Notre Dame Press, 2014)

4. I. Grybauskienè, Ž. Jankauskienè, and E. Kubilienè, EUREKA Soc. Humanit. 3, 17 (2019)

5. M. I. Boychenko, Filos. Osv. Philos. Educ. 25, 8 (2020)

6. C. Voegtlin and A. G. Scherer, Responsible Innovation and the Innovation of Responsibility: Governing Sustainable Development in a Globalized World (2017)

7. S. Gautam and S. Shyangtan, From Suffering to Surviving, Surviving to Living: Education for Harmony with Nature and Humanity (2021)

8. V. V. Zinchenko, M. I. Boichenko, and M. D. Popovych, in IOP Conf. Ser. Earth Environ. Sci. (2021)

9. Vereinte Nationen, Agenda 2030 - Resolution Der Generalversammlung Verabschiedet Am 25. September 2015 (2020)

10. B. Lucas, in 5th Int. Conf. Empl. Engagem. \&Training (2018), pp. 1-10

11. O. S. Polishchuk and O. V. Polishchuk, Filos. Osv. Philos. Educ. 19, 48 (2016) 